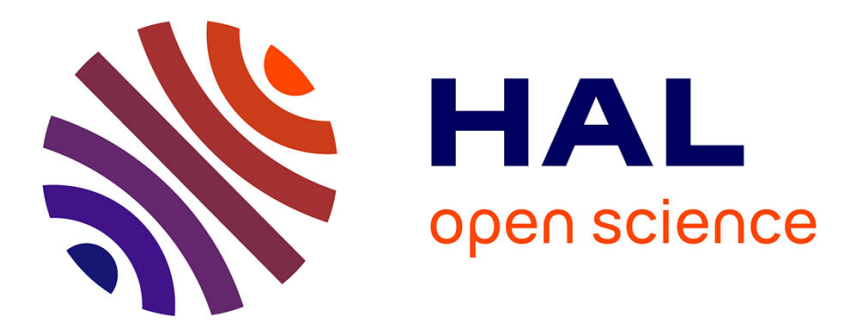

\title{
Treatment of multi-dentate surface complexes and diffuse layer implementation in various speciation codes
}

Johannes Lützenkirchen, Remi Marsac, Dmitrii Kulik, Timothy E Payne, Zhengrong Xue, Silvia Orsetti, Stefan B. Haderlein

\section{To cite this version:}

Johannes Lützenkirchen, Remi Marsac, Dmitrii Kulik, Timothy E Payne, Zhengrong Xue, et al.. Treatment of multi-dentate surface complexes and diffuse layer implementation in various speciation codes. Applied Geochemistry, 2015, 55, pp.128 - 137. 10.1016/j.apgeochem.2014.07.006 . hal01904344

\section{HAL Id: hal-01904344 \\ https://hal.science/hal-01904344}

Submitted on 24 Oct 2018

HAL is a multi-disciplinary open access archive for the deposit and dissemination of scientific research documents, whether they are published or not. The documents may come from teaching and research institutions in France or abroad, or from public or private research centers.
L'archive ouverte pluridisciplinaire HAL, est destinée au dépôt et à la diffusion de documents scientifiques de niveau recherche, publiés ou non, émanant des établissements d'enseignement et de recherche français ou étrangers, des laboratoires publics ou privés. 


\section{Treatment of multi-dentate surface complexes and diffuse layer implementation in various speciation codes}

\footnotetext{
Johannes Lützenkirchen $^{1 *}$, Remi Marsac ${ }^{1}$, Dmitrii A. Kulik ${ }^{2}$, Timothy E. Payne ${ }^{3}$

Zhengrong Xue ${ }^{4}$, Silvia Orsetti ${ }^{4}$, Stefan. B. Haderlein ${ }^{4}$

${ }^{1}$ KIT INE, Postfach 3640, 76021 Karlsruhe, Germany ( ${ }^{*}$ correspondence:

johannes.luetzenkirchen@kit.edu)

${ }^{2}$ Paul Scherrer Institut, 5232 Villigen PSI, Switzerland

${ }^{3}$ Australian Nuclear Science and Technology Organisation, Kirrawee DC, NSW 2232,

Australia

${ }^{4}$ Eberhard Karls Unversität Tübingen, Center for Applied Geoscience (ZAG), Hölderlinstrasse 12, 72074 Tübingen, Germany
} 


\begin{abstract}
Spectroscopic studies and atomistic simulations of (hydr)oxide surfaces show that ionic aqueous adsorbates can bind to one, two, three, or four surface oxygen atoms (sites), forming multi-dentate species in surface complexation reactions. The law of mass action (LMA) for such reactions can be expressed in several alternative scales of surface concentration (activity) and implemented in different ways in speciation. Unlike for mono-dentate surface complexes, the numerical value of the equilibrium constant is not independent of the choice of the surface concentration scale. Here, we show in a number of examples that the different formalisms implemented in popular speciation codes (MINEQL, MINTEQ, PHREEQC, and ECOSAT) yield different results for the same systems when the same parameters are used. We conclude that it is very important to generate general equations to easily transfer stability constants between the different concentration scales. It is of utmost importance for application of these models to reactive transport that the implementation in both the model fitting and speciation codes and in the transport codes is transparent to users.

We also point to the problem that the implementation of the diffuse layer formalism in the codes is not necessarily the general one. Thus, codes like VisualMinteq or MINEQL involve the Gouy-Chapman equation, which is limited to symmetrical (z:z) electrolytes, while PHREEQC and ECOSAT use general equations. Application of the former two to environmental problems with mixed electrolytes will therefore involve an inconsistency.
\end{abstract}

Keywords: Surface complexation model, speciation, multi-dentate surface complexes, GouyChapman equation 


\section{INTRODUCTION}

The uptake of chemical species on the surfaces of minerals from aqueous solutions, usually termed 'adsorption', plays a crucial role in the retention of hazardous cations and anions. The extent of adsorption is strongly dependent upon the local chemical environment, and it is therefore necessary to have realistic models for sorption processes to generate more defensible predictions. Such models can be developed utilising the same thermodynamic approaches as those applied in solution chemistry, using chemical reactions with associated stoichiometry and equilibrium constants, known as surface complexation models (SCMs). Kallay et al. (2011) provided a recent overview of the thermodynamics of mono-dentate reactions at solid/ liquid interfaces.

Initially, surface reactions were determined on the basis of analogy with the structure of mononuclear aqueous complexes, and equilibrium constants were fitted against the macroscopic (experimental) sorption data. Nowadays, surface complexation reactions are being formulated with the input from spectroscopic studies or from detailed atomistic (mechanistic) models of the mineral-water interface.

With the advent of spectroscopic techniques that probe the structure of surface species (Ponthieu et al., 2006; Sherman, 2009, Sherman et al., 2008; Sylwester et al., 2000; Machesky et al., 2006; Zhang et al., 2004; and refs therein), many adsorbed cations were found to be coordinated not only to one but to two, three or four surface oxygens, and represented accordingly in SCMs as multi-dentate surface complexes. Such bi-, tri- or tetra-dentate surface species have been identified in many solid/liquid systems, encompassing both cation and anion adsorption to surface functional groups.

The treatment of multi-dentate surface complexes is possible in various ways. Wang and Giammar (2013) give a recent overview for bidentate surface complexes and related pitfalls in adsorption modelling. This discussion has some history (Benjamin, 2002). Furthermore, while the present manuscript was under review, Gustafsson and Lumsdon (2014) showed how the 
wrong handling of bidentate surface complexes could induce unwarranted conclusions. In the present paper, we illustrate that different numerical formalisms have been implemented in available codes. Consequently, it would be helpful if the differences can be made transparent for the user community.

Another subtle detail is in the treatment of the diffuse part of the double layer in electrostatic models. While some codes document the use of the Gouy-Chapman equation (e.g. FITEQL), other codes have the general treatment implemented (e.g. ECOSAT). The difference is that the Gouy-Chapman equation is valid for symmetrical electrolytes only. This would mean that in general environmental settings, with a mixture of electrolytes, the diffuse part of the double layer cannot be correctly described with the Gouy-Chapman equation. While the effect on the overall calculations of the surface equilibria is probably minor in most cases, it can be of more importance in certain cases.

The aim of the present paper is to make the reader aware of existing differences between codes in treatment of adsorption involving multi-dentate surface species, and to show that the treatment of the diffuse part of the double layer is not necessarily general.

\section{Multi-dentate surface complexes}

\subsection{Formalism}

A general surface complexation reaction can be written in two ways

$d>\mathrm{SOH}^{\mathrm{z}}+M^{\mathrm{x}}+\mathrm{wH}_{2} \mathrm{O} \leftrightarrow(>\mathrm{SO})_{d} M(\mathrm{OH})_{\mathrm{w}}{ }^{\mathrm{x}+d z-\mathrm{w}}+(d+\mathrm{w}) \mathrm{H}^{+}$

$\left(>S \mathrm{SH}^{\mathrm{z}}\right)_{d}+M^{\mathrm{x}}+\mathrm{wH}_{2} \mathrm{O} \leftrightarrow(>S \mathrm{~S})_{d} M(\mathrm{OH})_{\mathrm{w}}{ }^{\mathrm{x}+d \mathrm{z}-\mathrm{w}}+(d+\mathrm{w}) \mathrm{H}^{+}$

$>\mathrm{SOH}$ denote surface sites, $\mathrm{z}$ and $\mathrm{m}$ denote charges, and $d$ and $\mathrm{w}$ are stoichiometric coefficients. While the mass balance equations associated with both equations would be identical, the mass law equations will differ for "denticity" $d>1$.

$$
\begin{aligned}
& K_{M}{ }^{i n t, d}=\left[(>S O){ }_{d} M(\mathrm{OH})_{\mathrm{w}}{ }^{\mathrm{x}+d z-\mathrm{w}}\right] \times\left[\mathrm{H}^{+}\right]^{d+w} \times\left[>S \mathrm{SH}^{\mathrm{z}}\right]^{-d} \times\left[M^{\mathrm{x}}\right]^{-1} \\
& K_{M}^{i n t}=\left[(>\mathrm{SO})_{d} M(\mathrm{OH})_{\mathrm{w}}{ }^{\mathrm{x}+d z-\mathrm{w}}\right] \times\left[\mathrm{H}^{+}\right]^{d+w} \times\left[\left(>S \mathrm{SH}^{\mathrm{z}}\right)_{d}\right]^{-1} \times\left[M^{\mathrm{x}}\right]^{-1}
\end{aligned}
$$


Here, $K_{M}{ }^{i n t}$ stands for the intrinsic equilibrium constant; we assume that the activity of water is constant, and use molarities instead of activities for the remaining species. Also we initially ignore the possibility of multi-nuclear complexes (in $M^{x}$ ) and omit the electrostatic factors. The set of equations (1) will also be referred to as formalism 1, while the set of equations (2) will be referred to as formalism 2 .

The important difference between formalism 1 and 2 is that in latter the ratio between concentration terms for surface species does not depend on the denticity $d$, while for the former it does. The consequence for formalism 1 is that a sorbent concentration term will ultimately appear, which involves correction of the stability constant in an appropriate way. This has been known for a long time and is included in textbooks (Sigg and Stumm, 1989; 1996; Sigg, Stumm and Behra, 1992). Interestingly, in the textbook by Stumm and Morgan (1990), only formalism 2 is mentioned. A detailed derivation can be found in the recent review by Wang and Giammar (2013).

A debate about the formal treatment, i.e. eqs. (1) vs. (2), still exists. An argument in favor of 1 would be that multiple bonds on the surface must be formed, and that the adsorbing species $M^{\mathrm{x}}$ has various possibilities to coordinate to available function groups on the surface. Such reasoning ultimately requires consideration of the surface structure (i.e. how the sites are arranged that are involved in the bonding). Arguments in favor of 2 would come from comparison to ligands like oxalate, where a single oxalate forms a bidentate complexe with metal ions in solution. This would never involve a square in the respective mass law equation. On the surface, similar to a dissolved ligand like oxalate, the functionalities are pre-arranged. No effect of solid concentration on the stability constant would result from eq (2).

In general, any treatment will fail when the surface coverage is high, and the possibilities for forming multidentate surface complexes become restricted. A simple mass law equation/mass balance treatment cannot handle this situation correctly if $d>1$. 
In case of eq (1), ultimately a second debate evolves about the best concentration scale to use, including molarities/molalities, mole fractions, or coverage fractions (Kulik, Lützenkirchen and Payne, 2010; Wang and Giammar, 2013).

\subsection{Consequences for the treatment in speciation codes}

Formalism 2 is exclusively possible with codes that allow distinction between the mass action law equation and the mass balance coefficients.

Formalism 1, as implemented in a given code, is currently restricted to one of the concentration scales per code, though it could be made more general. For the ECOSAT code, for example, the precise treatment has been described by Venema et al. (1996). In the ECOSAT implementation, the treatment is extended to multidentate surface species involving more than one kind of surface sites. While this seems to complicate the situation, because again various possible ways of defining the stability constants may exist, given that the implementation in the various codes and with respect to published parameters are known, the appropriate corrections can be made (Kulik, Lützenkirchen and Payne, 2010).

In the present comparison, we apply the codes ECOSAT, FITEQL, PHREEQC, and VISUALMINTEQ (references to the codes can be fined in the REFERENCES section). We compare formalism 1 within different codes, starting with a single site model and continuing to the more general case where different kinds of surface sites contribute to a multidentate surface complex. In principle this may also extend to different kinds of surfaces that interact as described by Lützenkirchen and Behra (1996). In particular, we compare the results obtained with the different codes on given examples to illustrate that the codes employ different implementations. In some examples we also involve a comparison between the two formalisms for bidentate complexes using FITEQL. Formalism 1 will then be denoted as FITEQL (1) and formalism 2 as FITEQL (2). 


\section{Diffuse layer potential}

\subsection{Formalism}

In most electrostatic surface complexation models, a distinct treatment of the diffuse part of the electrical interfacial layer (EIL) is included. The simplest treatment involves the GouyChapman equation, which relates the potential of the onset of the diffuse layer $\left(\Psi_{d}\right)$ to the diffuse layer charge $\left(\sigma_{\mathrm{d}}\right)$, as given in equation 3 .

$\sigma_{d}=(8000 \varepsilon R T I)^{1 / 2} \sinh \left(z F \Psi_{d} / 2 R T\right)$

In the above equation, $\mathrm{R}, \mathrm{T}$ and $\mathrm{F}$ have their usual meaning, $\varepsilon$ is the permittivity of the medium, which changes with composition under ambient conditions, and $\mathrm{z}$ is the valence of the symmetrical electrolyte, i.e. $\mathrm{z}=1$ for $1: 1, \mathrm{z}=2$ for $2: 2$ electrolyte, etc. I is the aqueous ionic strength, which has to be given in the appropriate units (molar or molal). I can be fixed at a given value by a background electrolyte (usually 1:1 electrolytes are used). Equation (3) does not apply to asymmetrical electrolytes like 2:1 (such as $\mathrm{CaCl}_{2}$ ) or to mixtures of symmetrical with asymmetrical electrolyes (i.e. general solution compositions). The codes typically allow for self-consistent calculation of the overall ionic strength, which would for example include changes in I due to $\mathrm{pH}$ adjustments in very acidic or basic regions, where the background electrolyte concentration is changed.

The general relation between the diffuse layer charge and potential as implemented in the ECOSAT code is reproduced in equation (4):

$\sigma_{\mathrm{d}}=(2000 \varepsilon \mathrm{RT})^{1 / 2}\left\{\Sigma[\mathrm{i}]\left(\exp \left(-\mathrm{z}_{\mathrm{i}} \mathrm{F} \Psi_{\mathrm{d}} / \mathrm{RT}\right)-1\right)\right\}^{1 / 2}$

Here, [i] is the concentration of a dissolved species and $\mathrm{z}_{\mathrm{i}}$ is its charge.

Compared to equation (3), equation (4) always involves the full aqueous speciation in the sum, making the numerical solution of the overall equilibrium problem more complex. 


\subsection{Consequences for the treatment in speciation codes}

The relevance of the diffuse layer for the equilibrium calculations is strongly dependent on the type of electrostatic model used. Using the purely diffuse layer model, it is expected that the effect is maximum. In this case, the relation between the surface charge and potential that directly affects the state of the adsorbed ions will be incorrect whenever the Gouy-Chapman equation (3) is used with asymmetrical electrolytes. For models including a Stern layer, the diffuse layer part is mainly associated to the overall electroneutrality condition, and the effect of using the inappropriate equation is probably minor. The important point that we want to make is that the users have to become aware of this problem, in particular because the generalized two layer models for hydrous ferric oxide (Dzombak and Morel, 1990), goethite (Mathur and Dzombak, 2006) and gibbsite (Karamalidis and Dzombak, 2010) use the purely diffuse layer model. These data sets are extensively applied to environmental settings with mixed electrolyte solutions. In the present code comparison, we will specify which equation is implemented in the codes ECOSAT, FITEQL, PHREEQC, and VISUALMINTEQ.

\section{Examples of computations for multi-dentate surface complexes}

The aim of the modeling exercises that are reported in the following was to illustrate the effects that arise from confusion of the intrinsic stability constants obtained using different codes or code combinations. The problem is related to the lack of knowledge about how the various codes operate, or how individual authors report stability constants.

\subsection{Multi-dentate surface complexes involving one kind of surface site}

We have selected a few examples. In one of them, we systematically compare the mono-dentate surface complexation calibration with higher denticity cases. To simplify the exercise, only one experimental adsorption edge is considered (i.e. the parameters are determined for a single set of experimental conditions). The basis for all modeling of metal 
ion adsorption is the acid-base model for the respective solid. This model, whenever required, was obtained from fitting the surface charge density vs. $\mathrm{pH}$ data to a single-site $1 \mathrm{pK}$ Basic Stern model involving electrolyte binding.

The first example system involves uranium(VI) adsorption on the quartz surface. For quartz, the classical $2 \mathrm{pK}$ scheme is in agreement with the MUSIC model, but one protolysis constant is sufficient to describe the titration results. In this first case, spectroscopy and theory suggest that bi-dentate complexes of uranyl are formed on silanol surface groups (Dent et al., 1992; Reich et al. 1996, 1998, Greathouse et al., 2002). In SCM calculations, we used the aqueous speciation database for uranium from NEA TDB (Guillaumont et al., 2003) with the Davies equation for aqueous activity coefficients:

$$
\log _{10} \gamma_{j}=-A_{\gamma} z_{i}^{2}\left(\frac{\sqrt{I}}{1+\sqrt{I}}-0.3 I\right)
$$

where $\gamma_{j}$ is the molal activity coefficient of individual aqueous species of charge $z_{j}, I$ has been defined above, and $A_{\gamma}$ is the Debye-Hückel coefficient.

The second test case involves the $\mathrm{Eu}-\mathrm{TiO}_{2}$ system studied by Bouby et al. (2010). Their system-specific EXAFS data favor mono-dentate Eu binding, while X-ray standing waves results (Machesky et al., 2006) support tetra-dentate binding of rare earth element (REE) cations to that rutile. To limit the model variants, we did not consider tetra-dentate binding of sodium in the acid-base model when fitting the surface charge and zeta-potential data of Bouby et al. (2010). The aqueous speciation database included hydroxocomplexes of $\mathrm{Eu}(\mathrm{III})$ with the following stability constants: $\log \beta_{1}=6.8 ; \log \beta_{2}=12.9 ; \log \beta_{3}=15.8$ used with the Davies equation, as in Bouby et al. (2010). Europium was considered to be equivalent to Americium, and consequently the critically evaluated hydrolysis data for Americium were used. 
The third case treats the Cu-goethite system studied by Peacock and Sherman (2004) and Sherman (2009), which put forward spectroscopic and structural arguments in favor of the corner-sharing bi-dentate and bi-nuclear tri-dentate $\mathrm{Cu}^{\mathrm{II}}$ surface complexes, and modeled the system with a 2pK-DLM using the FITEQL code. In this case, no refitting of acid-base parameters was required, and the parameters were taken from the above-cited references.

The last case in this section involves adsorption of $\mathrm{Fe}(\mathrm{II})$ to goethite with the formation of two bidentate surface complexes.

\subsubsection{The uranyl-quartz system (mono- vs bi-dentate case)}

This system is characterized by the following underlying acid-base model, as given by the reaction equations and the corresponding equilibrium constants.

$$
\begin{array}{ll}
\mathrm{Si}-\mathrm{OH}^{0} \leftrightarrow \mathrm{Si}-\mathrm{O}^{-}+\mathrm{H}^{+} & \log _{10} K_{H}^{\mathrm{int}, 1}=-7.90 \\
\mathrm{Si}-\mathrm{OH}^{0}+\mathrm{Na}^{+} \leftrightarrow \mathrm{Si}-\mathrm{O}^{-\cdots} \mathrm{Na}^{+}+\mathrm{H}^{+} & \log _{10}{ }^{\prime} K_{N a}^{\mathrm{int}, 1}=-6.93
\end{array}
$$

The specific surface area was $A_{S}=0.33 \mathrm{~m}^{2} \mathrm{~g}^{-1}$ and solid concentration was $c_{S}=100 \mathrm{~g}$ $\mathrm{dm}^{-3}$. We used a site density $\mathrm{N}_{S}=4.6 \mathrm{~nm}^{-2}\left(\Gamma_{S}=7.64 \cdot 10^{-6} \mathrm{~mol} \mathrm{~m}^{-2}\right)$ and the fitted capacitance density (BSM) $\mathrm{C}_{1}=1.45 \mathrm{~F} \mathrm{~m}^{-2}$. Assuming mono-dentate binding, the following reaction yielded the best-fit model obtained using FITEQL (Figure 1A).

$$
\mathrm{Si}-\mathrm{OH}^{0}+\mathrm{UO}_{2}{ }^{2+} \leftrightarrow \mathrm{Si}^{-} \mathrm{OUO}_{2}{ }^{+}+\mathrm{H}^{+} \quad \log _{10}{ }^{1} K_{U}^{\mathrm{nn}, \downarrow}=-0.64
$$

In our simplified model, we did not attempt to achieve a better fit to the data by involving two or more reactions or by using Charge Distribution (CD). The black line on Figures 1A and 1B shows a complete CD-MUSIC benchmark model for this data set (scattered diamonds), calibrated for this system on a comprehensive experimental data set (Lützenkirchen, 2004).

Using a FITEQL based code to fit a bi-dentate reaction to the data under the same premises results in an optimum description with the following reaction:

$$
2\left(\mathrm{Si}-\mathrm{OH}^{0}\right)+\mathrm{UO}_{2}{ }^{2+} \leftrightarrow(\mathrm{Si}-\mathrm{O})_{2} \mathrm{HUO}_{2}{ }^{+}+\mathrm{H}^{+} \quad \log _{10} K_{U}^{\mathrm{int}, 2}=2.96
$$


Both models perform equally well (Figure 1A). In the next step, the two model variants were used with ECOSAT; the corresponding "blind predictions" are shown on Figure $1 \mathrm{~B}$, where the mono-dentate constant from eq (8) yields the same curve as on Figure $1 \mathrm{~A}$, whereas the bi-dentate constant from eq (9) results in a prediction of $100 \%$ adsorption in the whole $\mathrm{pH}$ interval.
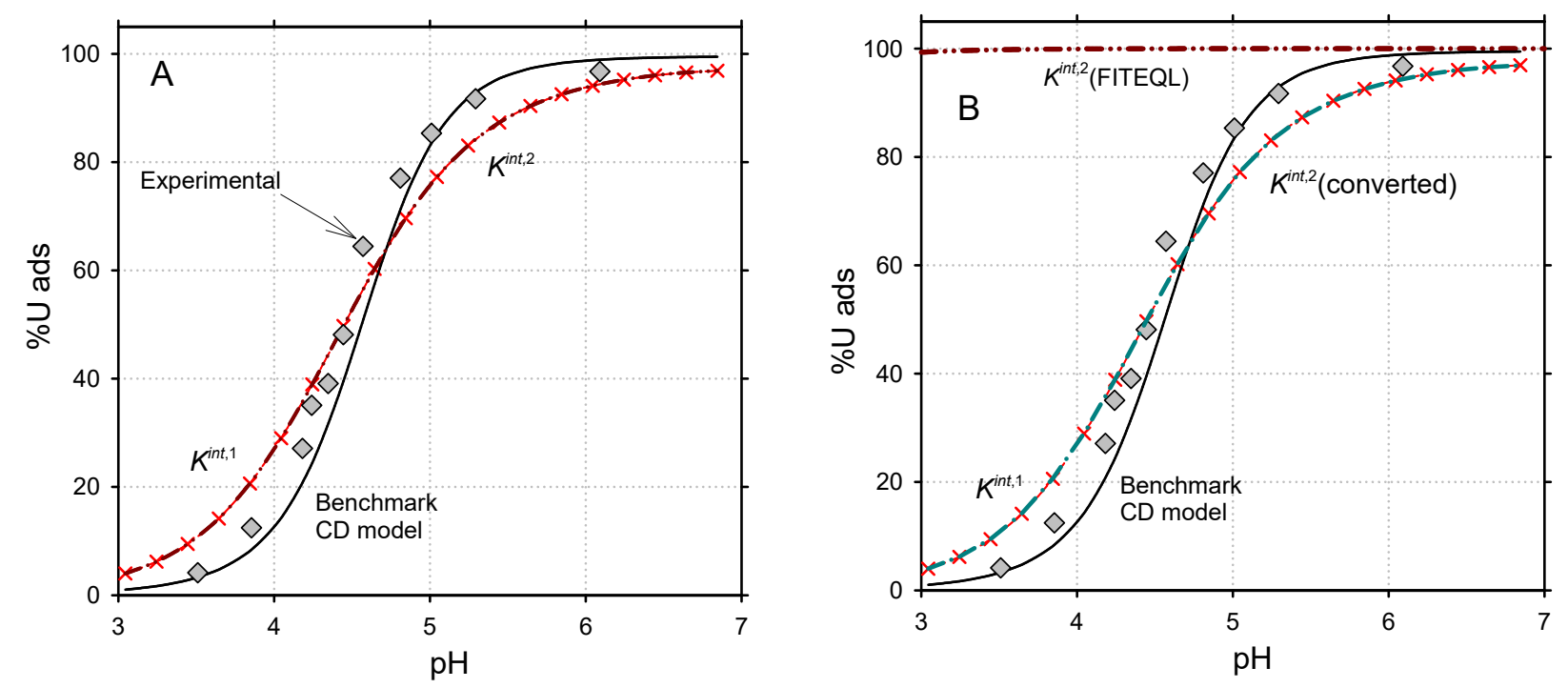

Figure 1. Comparison of SCM fits for the uranyl-quartz system for mono- ( $K^{\text {intl }}$, crosses $)$ and bi-dentate cases. FITEQL fits for a simplified model (A), and forward ECOSAT calculations (B) without- and with re-scaled value of $K^{\text {int2 }}$ for $\mathrm{U}^{\mathrm{VI}}$ adsorption. Diamonds represent experimental data, thin solid curves - the 'benchmark' CD-MUSIC model.

We see that direct application of the molar intrinsic constant ${ }^{\mid} K_{U}^{\mathrm{int}, 2}=10^{2.96}$ in forward ECOSAT calculation results in a large over-prediction biased by 3.6 orders of magnitude, far more than any reasonable analytical or fitting error.

Rescaling the FITEQL-fitted bi-dentate constant ${ }^{\mid} K_{U}^{\mathrm{int}, 2}$ to the surface mole fraction scale $\theta$ concentration scale used in the ECOSAT input by applying the correction given by 
Venema et al. (1996) with total molar concentration of surface sites $[\equiv]_{\mathrm{TOT}}=2.521 \cdot 10^{-4} \mathrm{M}$ leads to the same value as that for the mono-dentate binding constant

$$
2\left(\mathrm{Si}-\mathrm{OH}^{0}\right)+\mathrm{UO}_{2}{ }^{2+} \leftrightarrow(\mathrm{Si}-\mathrm{O})_{2} \mathrm{HUO}_{2}{ }^{+}+\mathrm{H}^{+} \quad \log { }^{\theta} K_{U}^{\mathrm{int}, 2}=-0.64
$$

Use of this value (denoted as converted in Figure 1B) reproduces exactly the FITEQL result.

\subsubsection{The $\mathrm{Eu}$-rutile $\left(\mathrm{TiO}_{2}\right)$ system (mono-vs tetra-dentate case)}

In the experiments (performed in $0.1 \mathrm{M} \mathrm{NaClO}_{4}$ ), the specific surface area was $A_{S}=50.6 \mathrm{~m}^{2}$ $\mathrm{g}^{-1}$ and the solid concentration was $c_{S}=0.1 \mathrm{~g} \mathrm{dm}^{-3}$; the total Eu concentration was $1.23 \cdot 10^{-6}$

M. We used a single-site BS (basic Stern) model with the site density $\Gamma_{S}=2.0 \cdot 10^{-5} \mathrm{~mol} \mathrm{~m}^{-2}$ (ca. $12 \mathrm{~nm}^{-2}$ ) and the fitted capacitance density $\mathrm{C}_{1}=0.71 \mathrm{~F} \cdot \mathrm{m}^{-2}$. The surface protolysis reactions were written in a 'simple' $1 \mathrm{pK}$ fashion:

$$
\begin{array}{ll}
\mathrm{Ti} \equiv \mathrm{O}^{-1 / 2}+\mathrm{H}^{+} \leftrightarrow \mathrm{Ti} \equiv \mathrm{OH}^{+1 / 2} & \log _{10} K_{H}^{\mathrm{int}, 1}=6.27 \\
\mathrm{Ti} \equiv \mathrm{O}^{-1 / 2}+\mathrm{Na}^{+} \leftrightarrow \mathrm{Ti} \equiv \mathrm{O}^{-1 / 2 \ldots} \mathrm{Na}^{+} & \log _{10} K_{N a}^{\mathrm{int}, 1}=-0.63 \\
\mathrm{Ti} \equiv \mathrm{O}^{-1 / 2}+\mathrm{H}^{+}+\mathrm{ClO}_{4}{ }^{-} \leftrightarrow \mathrm{Ti} \equiv \mathrm{OH}^{+1 / 2 \ldots} \mathrm{ClO}_{4}{ }^{-} & \log _{10} K_{\mathrm{ClO} 4}^{\mathrm{int}, 1}=4.81
\end{array}
$$

The thin solid line on Figure 2A shows a benchmark CD-MUSIC model for the rutile surface using a mono-dentate $\mathrm{Eu}{ }^{\mathrm{III}}$ surface species, which was calibrated on a large set of data for this experimental system (Bouby et al., 2010). The simplified 1pK-based model fit (FITEQL) from the present modeling exercise (continuous red line on Figure 2A) shows a reasonable description of experimental data using a mono-dentate reaction

$$
\mathrm{Ti} \equiv \mathrm{O}^{-1 / 2}+\mathrm{Eu}^{3+} \leftrightarrow \mathrm{Ti}=\mathrm{OEu}^{2.5+} \quad \log _{10} K_{E u}^{\mathrm{int}, 1}=7.99
$$

Spectroscopic evidence reported by Machesky et al. (2006) supports a 2+2-dentate binding of REE cations such as $\mathrm{Eu}^{\mathrm{III}}$ to the rutile surface, which in our simplified single-site model case is represented by a tetra-dentate reaction 
$4\left(\mathrm{Ti} \equiv \mathrm{O}^{-1 / 2}\right)+\mathrm{Eu}^{3+} \leftrightarrow(\mathrm{Ti}=\mathrm{O})_{4} \mathrm{Eu}^{+} \quad \log _{10} K_{E u}^{\mathrm{int}, 4}=21.13$

This FITEQL-optimized intrinsic constant leads to a model curve (green continuous line on Figure 2A) that is slightly shifted to the left from the "monodentate" curve, but has the same shape. This small shift may be due to the difference in the surface species charge.

Application of the same constant with the same tetra-dentate reaction (12b) in an ECOSAT forward modeling run results in substantial over-prediction (see Figure 2B) at any pH. Re-scaling the constant with the total site molarity $[\equiv]_{\mathrm{TOT}}=c_{S} A_{S} \Gamma_{S}=0.0001008 \mathrm{M}$ results in a value $\log _{10}{ }^{\theta} K_{\mathrm{Eu}}^{\mathrm{int}, 4}=9.14$ (for the reaction $4\left(\mathrm{Ti} \equiv \mathrm{O}^{-1 / 2}\right)+\mathrm{Eu}^{3+} \leftrightarrow(\mathrm{Ti} \equiv \mathrm{O})_{4} \mathrm{Eu}^{+}$), with which the same forward-modeling curve is obtained in ECOSAT (Figure 2B) as that for log $K_{E u}^{\mathrm{int}, 4}=21.13$ in FITEQL calculations.

Conversely, the bias in $\log K_{E u}^{\text {int, } 4}$ value for this 4-dentate Eu surface complex relative to the $\log ^{\theta} K_{E u}^{\mathrm{int}, 4}$ value was 12 orders of magnitude in this system.
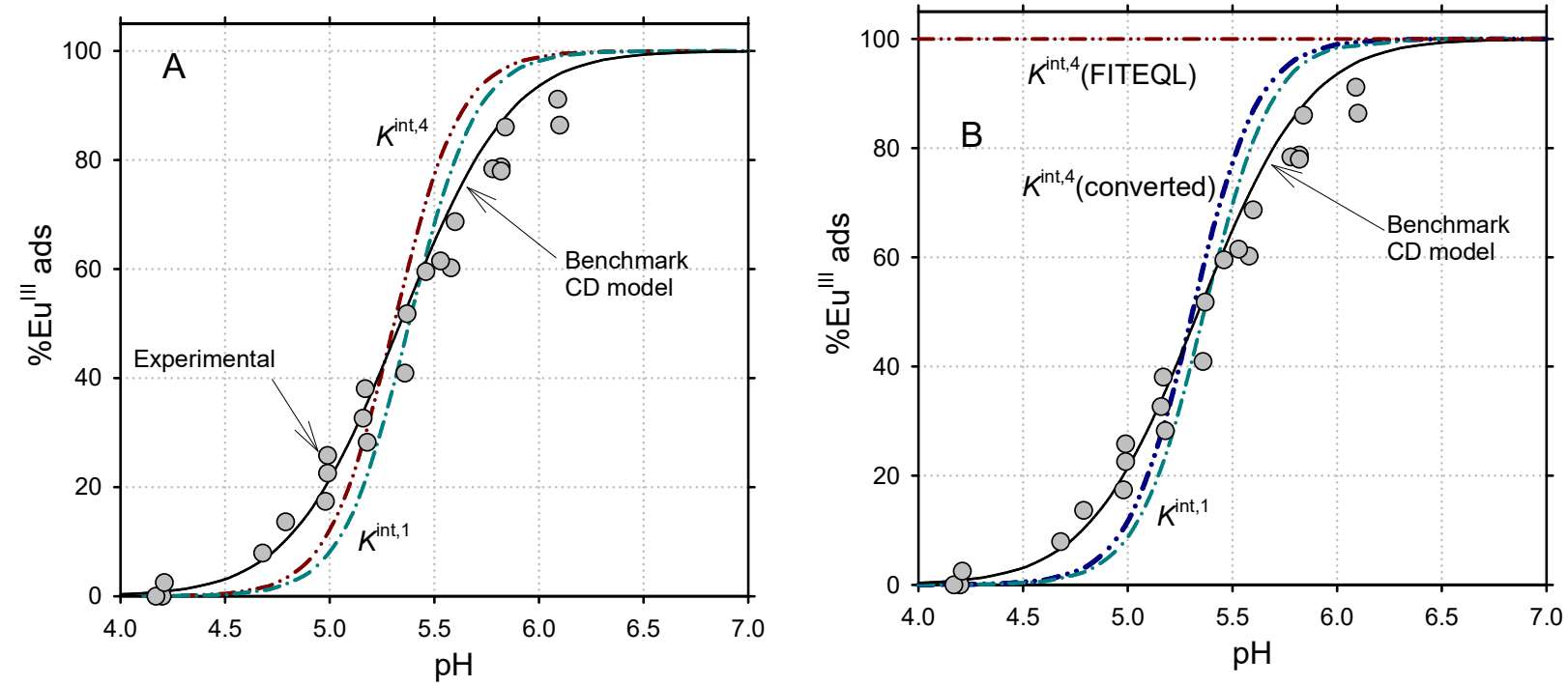

Figure 2. Comparison of SCM fits for the $\mathrm{Eu}^{\mathrm{III}}$-rutile system for mono- and tetra-dentate cases. FITEQL fits for a simplified model (A) and forward ECOSAT calculations (B) with the original and converted tetra-dentate intrinsic constant $K^{\text {int,4 }}$. Scattered circles represent experimental data. See text for explanations. 


\subsubsection{The Cu${ }^{I I}$-goethite system (bi- + tri-dentate case)}

Adsorption studies of $\mathrm{Cu}(\mathrm{II})$ on goethite $(\alpha-\mathrm{FeOOH})$ provides spectroscopic evidence for corner-sharing bi-dentate monomeric and tri-dentatedimeric $\mathrm{Cu}$ surface complexes (Peacock and Sherman, 2004; Sherman, 2009). These authors performed modeling using the FITEQL code with a DLM including the following surface species and intrinsic constants:

$>\mathrm{SOH}^{0}+\mathrm{H}^{+} \Leftrightarrow>\mathrm{SOH}_{2}^{+} \quad \log K_{\mathrm{a} 1}=6.78$

$>\mathrm{SOH}^{0} \Leftrightarrow>\mathrm{SO}^{-}+\mathrm{H}^{+} \quad \log K_{\mathrm{a} 2}=-10.10$

$2>\mathrm{SOH}+\mathrm{Cu}^{2+}+2 \mathrm{H}_{2} \mathrm{O}=(>\mathrm{SOH})_{2} \mathrm{Cu}(\mathrm{OH})_{2}+2 \mathrm{H}^{+} \quad \log \mathrm{K}_{\mathrm{Cu}}^{\mathrm{int}, 2}=-3.1$

$3>\mathrm{SOH}+2 \mathrm{Cu}^{2+}+3 \mathrm{H}_{2} \mathrm{O}=(>\mathrm{SOH})_{2}>\mathrm{SOCu}_{2}(\mathrm{OH})_{3}+4 \mathrm{H}^{+} \log \mathrm{K}_{2 \mathrm{Cu}}^{\mathrm{int}, 3}=-5.25$

In their experiments, specific surface area was $A_{S}=32.73 \mathrm{~m}^{2} \cdot \mathrm{g}^{-1}$; solid concentration was $c_{S}=$ $3.33 \mathrm{~g} \cdot \mathrm{dm}^{-3}$; the electrolyte concentration was $0.1 \mathrm{M} \mathrm{NaNO}_{3}$, and $[\mathrm{Cu}]_{\mathrm{TOT}}=3.93 \cdot 10^{-4} \mathrm{M}$. The site number density parameter for goethite was set to 6 sites $\cdot \mathrm{nm}^{-2}\left(\Gamma_{S}=9.96 \cdot 10^{-6} \mathrm{~mol} \cdot \mathrm{m}^{-2}\right)$. The aqueous hydrolysis constants for $\mathrm{Cu}^{2+}$ are given in (Peacock and Sherman, 2004).

The goal of our numerical exercise was to find out whether (and how) this FITEQLfitted SCM can be reproduced with another speciation code (ECOSAT). The straightforward run (Figure 3A) of the $\mathrm{pH}$ adsorption edge in the ECOSAT with intrinsic constants taken from eqs $(15,16)$ resulted in ca. 1.3 units shift to lower $\mathrm{pH}$ relative to the experimental data.

However, after applying the correction with $[>\mathrm{S}]_{\mathrm{TOT}}=c_{S} A_{S} \Gamma_{S}=1.086 \cdot 10^{-3} \mathrm{M}$, leading to intrinsic constants expressed in surface mole fraction scale $\theta$,

$\log _{10}{ }^{\theta} K_{C u}^{\mathrm{int}, 2}=-3.1-2.96=-6.06 ; \quad \log _{10}{ }^{\theta} K_{2 C u}^{\mathrm{int}, 3}=-5.25-2.96 \cdot 2=-11.17$

the produced model curves were close to the original DLM of Peacock and Sherman (2004), though not in perfect agreement (Figure 3B). The small discrepancies were probably not due to differences in the treatment of aqueous activity coefficients, but rather arise from the difference between $\mathrm{pH}$ and $-\log \left[\mathrm{H}^{+}\right]$scales in plotting the modeling results or in the fitting (this difference amounts to $0.11 \log$ units for the ionic strength involved). Our fitting exercise 
was done in the molar concentration scale for all species involved, and subsequently, the proton concentration was recalculated to proton activity. As seen from this example, the magnitude of the $K^{\text {int }}$ correction factor is about $3 \log$ units for bi-dentate and about $6 \log$ units for tri-dentate surface species.
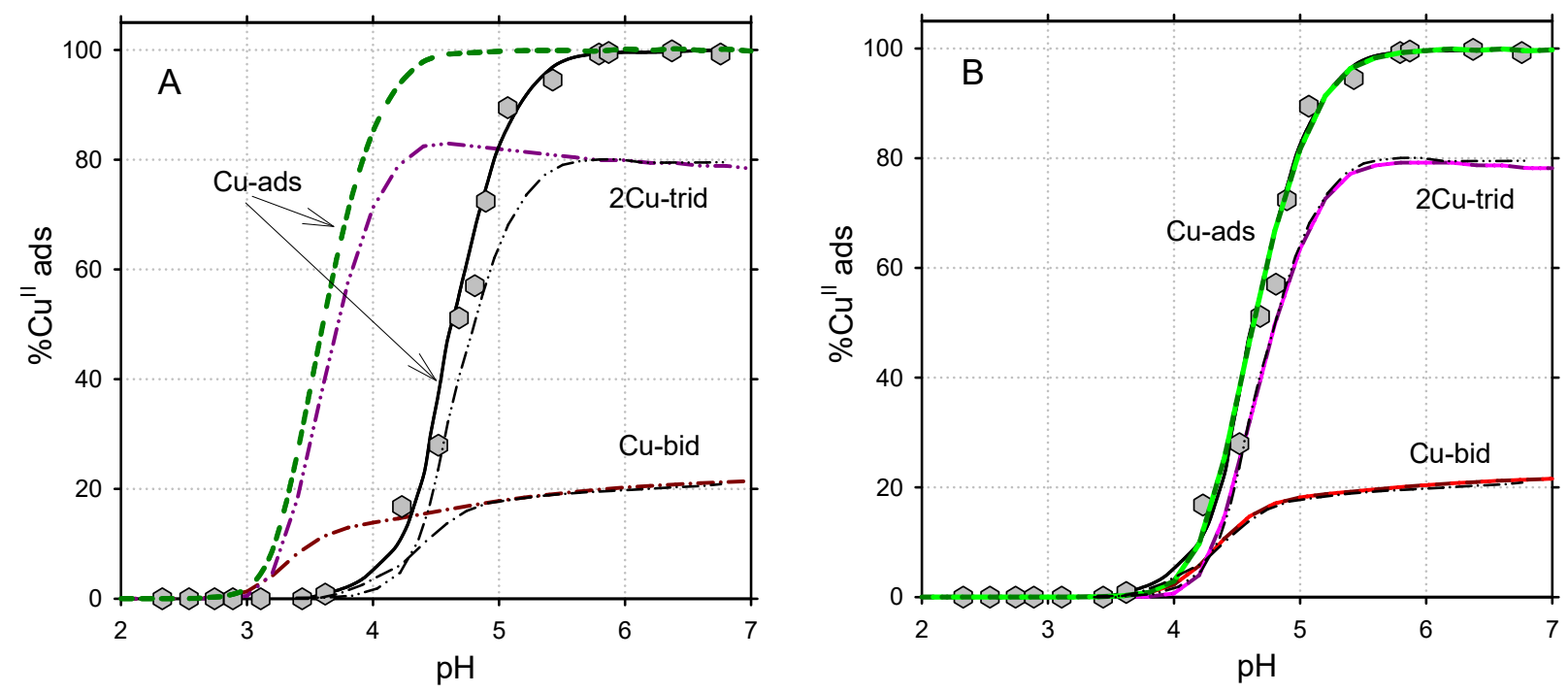

Figure 3. Copper $\mathrm{pH}$ adsorption edge in DLM for the $\mathrm{Cu}^{\mathrm{II}}$-goethite system with bi- and tridentate species from (Peacock and Sherman, 2004) (thin curves, scattered hexagons represent experimental data), re-modeled using the ECOSAT code (A) before and (B) after conversion of intrinsic adsorption constants.

Our modeling tests (which all keep the same EIL model parameters) demonstrate that in all cases, the numerical values of intrinsic adsorption constants may contain significant contributions related to the multiple denticity of surface complexes.

In this example, we also involve results obtained with VISUALMINTEQ and PHREEQC. The purpose was to determine which kind of formalism is implemented in these popular codes. According to the manuals, VISUALMINTEQ is exactly as ECOSAT. PHREEQC does not involve the same treatment as ECOSAT but defines a correction term involving maximum coverage of all sites. For only one site involved in a multidentate surface complex this leads to a correction term corresponding to the denticity d. 
Figure 4 shows that straightforward use of the published constants gives similar results as with ECOSAT, from which we infer that multidentate surface complexes within formalism 1 obtained by FITEQL need to be rescaled prior to use with both PHREEQC and VISUALMINTEQ as expected based on the manuals.

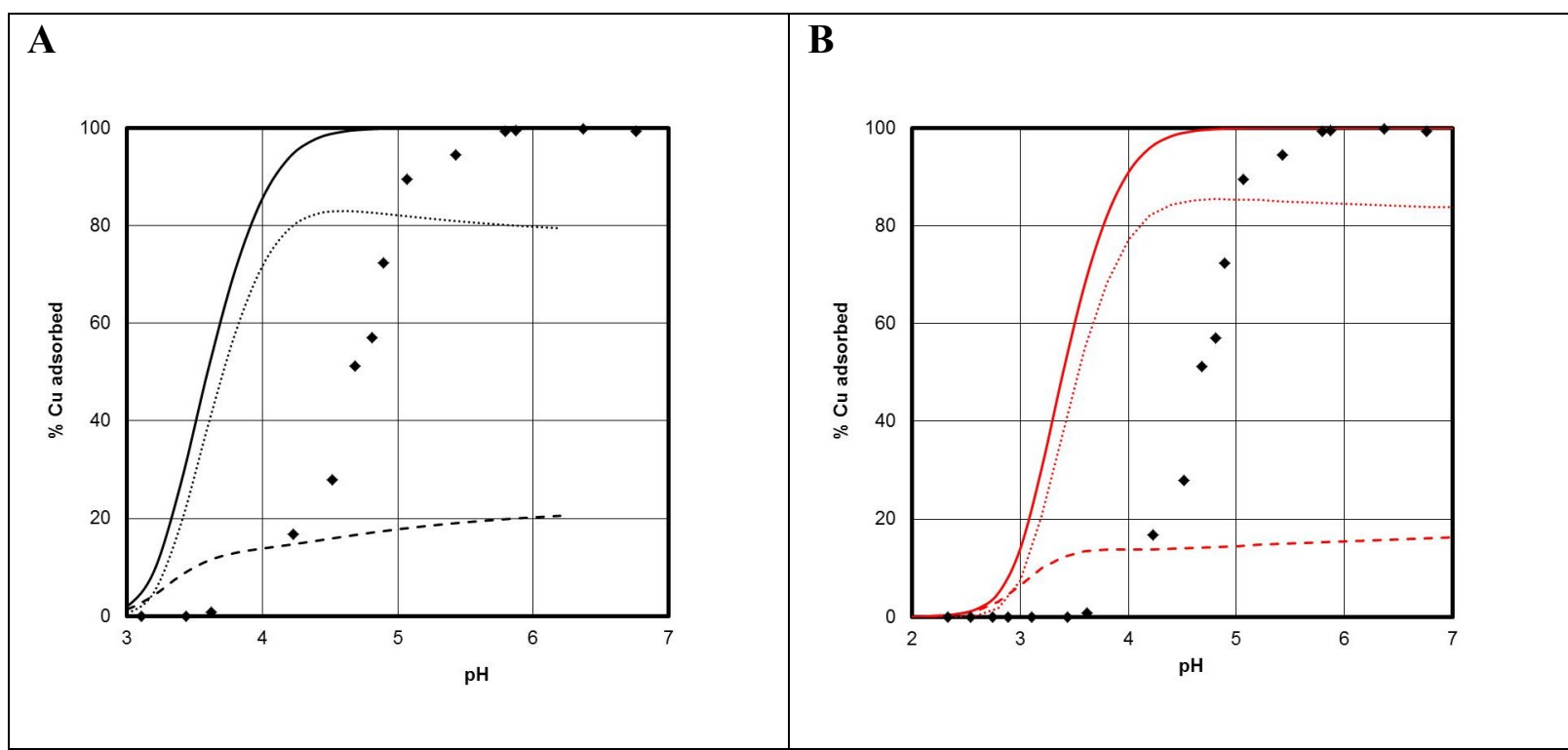

Figure 4. Copper $\mathrm{pH}$ adsorption edge in DLM for the $\mathrm{Cu}^{\mathrm{II}}$-goethite system with bi- and tridentate species from (Peacock and Sherman, 2004) modeled using the VISUALMINTEQ (A) and PHREEQC (B) without any conversion of FITEQL intrinsic adsorption constants.

\subsubsection{The Fe ${ }^{I I}$-goethite system (two bi-dentate surface complexes)}

Adsorption of $\mathrm{Fe}(\mathrm{II})$ on goethite $(\alpha-\mathrm{FeOOH})$ was extensively modelled by Hiemstra and van Riemsdijk (2007). Their final model involved two bidentate species, one of them involving electron transfer. Their model was built on a three plane EIL concept. The surface acid-base scheme is given below:

$$
\begin{array}{ll}
>\mathrm{Fe}_{\mathrm{x}} \mathrm{OH}_{\mathrm{y}}^{-0.5}+\mathrm{H}^{+} \Leftrightarrow>\mathrm{Fe}_{\mathrm{x}} \mathrm{OH}_{\mathrm{y}+1}{ }^{+0.5} & \log K_{H}^{i n t}=9.2 \\
>\mathrm{Fe}_{\mathrm{x}} \mathrm{OH}_{\mathrm{y}}^{-0.5}+\mathrm{Na}^{+} \Leftrightarrow>\mathrm{Fe}_{\mathrm{x}} \mathrm{OH}_{\mathrm{y}}^{-0.5 \cdots \mathrm{Na}^{+}} \quad \log K_{N a}^{i n t}=-0.61 \\
>\mathrm{Fe}_{\mathrm{x}} \mathrm{OH}_{\mathrm{y}}^{-0.5}+\mathrm{H}^{+}+\mathrm{Cl}^{-} \Leftrightarrow>\mathrm{Fe}_{\mathrm{x}} \mathrm{OH}_{\mathrm{y}+1}{ }^{+0.5} \cdots \mathrm{Cl}^{-} \quad \log K_{C l}^{\text {int }}=8.75
\end{array}
$$


Here, $\mathrm{x}=1$, and $\mathrm{y}=1$ for the singly co-ordinated sites $\left(3.45\right.$ sites $\left./ \mathrm{nm}^{2}\right)$ and $\mathrm{x}=3$, and $\mathrm{y}=0$ for the triply co-ordinated sites $\left(2.70\right.$ sites $\left./ \mathrm{nm}^{2}\right)$. Capacitances for the two layers were $0.92 \mathrm{~F} / \mathrm{m}^{2}$. The Fe(II) adsorption model was designed as follows:

$2>\mathrm{FeOH}^{-0.5}+\mathrm{Fe}^{2+}=\left[\left(>\mathrm{FeOH}^{-0.5}\right)_{2}\right]^{+0.73} \mathrm{Fe}_{\mathrm{II}}^{+1.27} \quad \log K_{\mathrm{Fe}}{ }^{i n t, 2}=8.47$

$2>\mathrm{FeOH}^{-0.5}+\mathrm{Fe}^{2+}+2 \mathrm{H}_{2} \mathrm{O}=\left(>\mathrm{FeOH}^{-0.5}\right)_{2}{ }^{+0.17} \mathrm{Fe}_{\mathrm{III}}(\mathrm{OH})_{2}{ }^{-0.17}+2 \mathrm{H}^{+} \log K_{\mathrm{FeOH}}{ }^{\text {int }, 2}=-9.31$

In our calculations, the specific surface area was $A_{S}=78 \mathrm{~m}^{2} \cdot \mathrm{g}^{-1}$; solid concentration was $c_{S}=$ $1.50 \mathrm{~g} \cdot \mathrm{dm}^{-3}$; the electrolyte concentration was $0.01 \mathrm{M} \mathrm{NaCl}$, and $\left[\mathrm{Fe}_{\mathrm{II}}\right]_{\mathrm{TOT}}=5.0 \cdot 10^{-4} \mathrm{M}$. No $\mathrm{Fe}(\mathrm{II})$ hydrolysis was considered in the aqueous phase. The results of the calculations are shown in Figure 5.

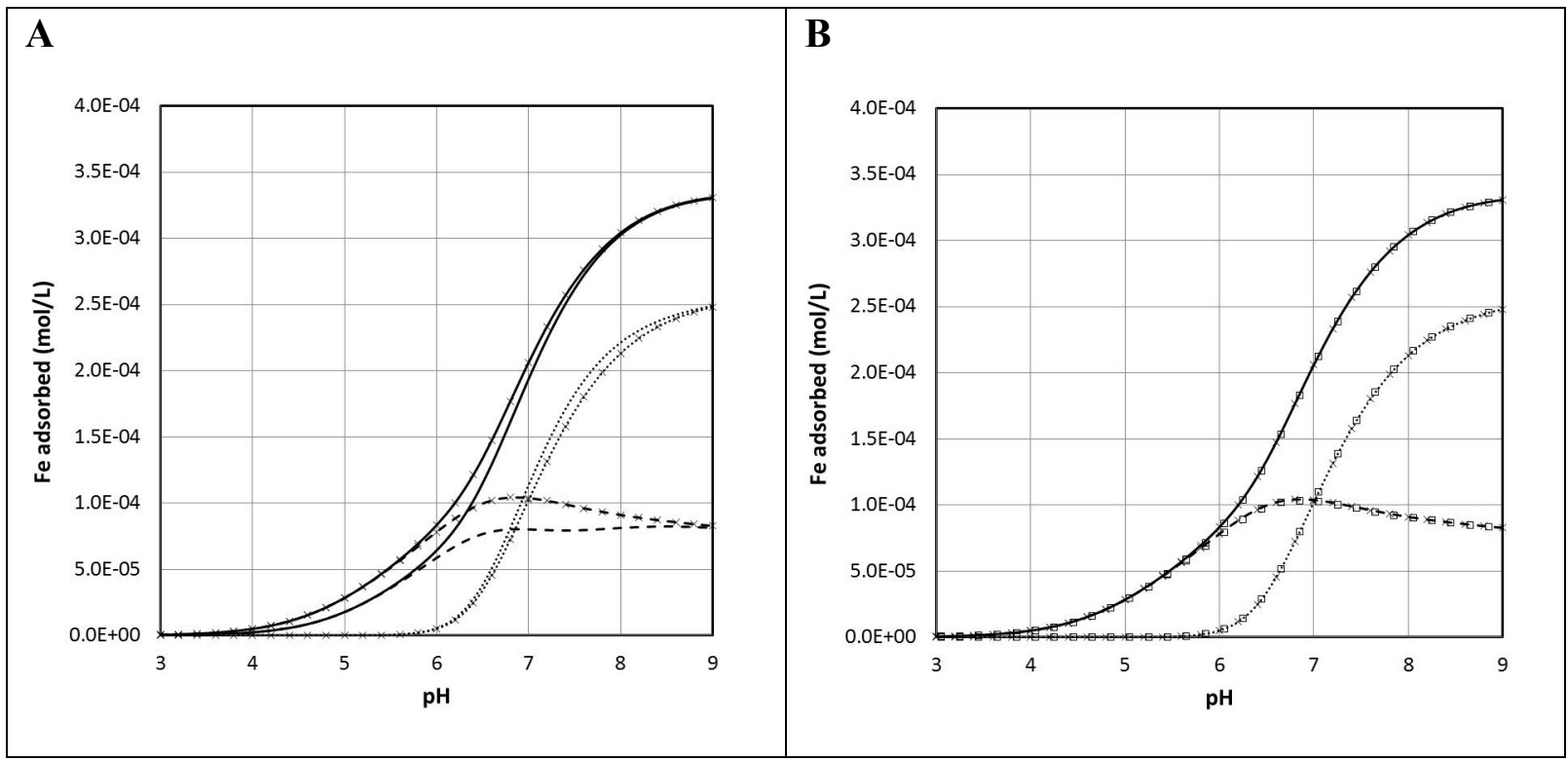

Figure 5. $\mathrm{Fe}(\mathrm{II})$ adsorption as a function of $\mathrm{pH}$ in CD-MUSIC on goethite. A: comparison between a PHREEQC calculations (lines) and an ECOSAT calculation (lines with crosses). B: comparison between ECOSAT calculation (lines with crosses) and a FITEQL calculation after applying the appropriate correction term (squares).

Figure 5A shows that in these calculations there is a shift of the PHREEQC calculation to higher $\mathrm{pH}$ compared to the ECOSAT results. According to Figure 5B FITEQL reproduces the ECOSAT calculations exactly within formalism 1 and an appropriate correction term. 


\subsection{Multi-dentate surface complexes involving two kinds of surface sites}

In this section, we consider the CD-MUSIC model for Cd adsorption to the goethite $(021)$ face. According to the model by Venema et al. (1996) the reaction occurs via the following equation

$2 \mathrm{FeOH}^{-1 / 2}+\mathrm{Fe}_{2} \mathrm{OH}^{\circ}+\mathrm{Cd}^{2+}=\left[\left\{(\mathrm{FeOH})_{2} \mathrm{Fe}_{2} \mathrm{OH}\right\}^{+1.16-1} \mathrm{Cd}^{+0.84}\right]^{+} \quad \log K_{C d}{ }^{\text {int,3 }}=9.0$

The ECOSAT inherent correction involves the term

$\log \left(\mathrm{S}_{\mathrm{s}}+\mathrm{S}_{\mathrm{d}}\right)-2 \log \mathrm{S}_{\mathrm{s}}-\log \mathrm{S}_{\mathrm{d}}$

where $\mathrm{S}$ is defined as product of suspension density (solid concentration), specific surface area and site density. We suspect that if included in the other codes (VISUALMINTEQ and PHREEQC)) these corrections may differ. They will depend on whether the multidentate surfaces are defined based on mole fractions (referenced either to individual sites or the total number of sites), surface coverage (again this might be referenced to the maximum coverage with respect to indivual site or all sites) or any other normalization. As pointed out above, these corrections may become huge. The correction term according to equation (22) for $1 \mathrm{~g} / 1$ and $20 \mathrm{~m}^{2} / \mathrm{g}$ is $7.7 \log$ units.

Figure 6A shows the results of straightforward application of the published parameters with the different codes. For FITEQL, the correction eq. (24) was used. According to Figure 6B PHREEQC as in the examples before does not reproduce those results. As pointed out before the corrections are different between PHREEQC and ECOSAT because according to the PHREEQC manual, the correction includes the denticity with respect to the surface sites as a denominator to the site concentration, in the case of a tridentate introducing a term $\log (3)=$ 0.478. This results in $\log K_{C d}^{\text {int } 3, P H R E E Q C}=9.48$, which exactly reproduces the results obtained by the other codes. In the case of bidentates, the correction would be $\log (2)=0.3$. The denomitor in PHREEQC allows for the mole fraction of multidentate surface complexes to 
become unity. It is not clear how this is handled for binuclear, multidentate surface complexes like in eq. (16).

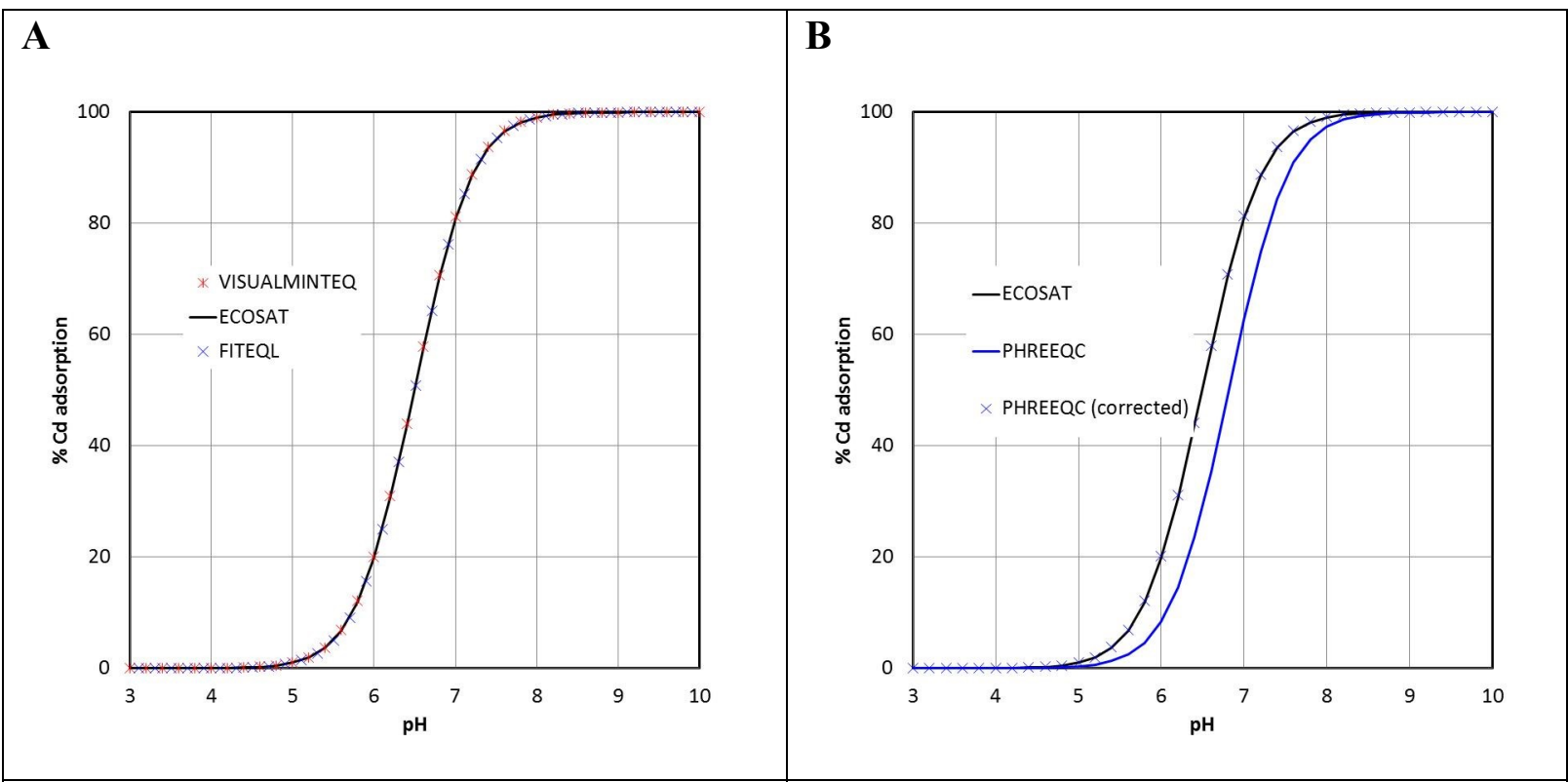

Figure 6. Cadmium adsorption as a function of $\mathrm{pH}$ in CD-MUSIC on goethite (021). A: Calculations using VISUALMINTEQ, ECOSAT and FITEQL. For FITEQL the ECOSAT based scheme was corrected. B: Calculations using ECOSAT and PHREEQC. PHREEQC (corrected) refers to a correction according to the PHREEQC manual.

\subsection{Summary for multi-dentate surface complexes}

To confirm the results of the previous two sections, we have built another series of calculations starting from monodentate surface complexes, and subsequently changing the system to a single bidentate complex on one site and subsequently on two sites. We use the example of $\mathrm{Zn}$ adsorption to HFO according to Dzombak and Morel (1990). The databases or thermodynamic parameters were taken from Dzombak and Morel (1990).

Figure 7 summarizes the findings. While for the monodentate case, straightforward application of the codes yields the same outcome in all cases (Figure 7A), the previously noted differences are repeated in the cases of multidentate species.

In particular, ECOSAT and VISUALMINTEQ calculations coincide in all cases. Molar scale used within FITEQL yields different curves independently of the formalism used. In this case, 
the ECOSAT based constants need to be rescaled using the appropriate functions, such as eq. (23) for the Cd-goethite case in the previous section. PHREEQC always produces underestimates compared to the ECOSAT reference, caused by the additional correction. Users of PHREEQC should refer to the documentation regarding the appropriate corrections. In summary, the calculations have shown that huge differences in calculation results may occur when constants from the literature are used without prior correction. While this has been pointed out by Venema et al. (1996) for the rescaling of ECOSAT intrinsic equilibrium constant in surface mole fraction scale to that in molar scale (implemented in codes like FITEQL, MINEQL, SOLGASWATER), users have to make sure they either use a code with the same implementation or consult the manuals to do appropriate corrections. Our results show that VISUALMINTEQ works exactly as ECOSAT, since in all cases the results from ECOSAT are exactly reproduced without adjustment of intrinsic constants.PHREEQC uses a different scaling. The transfer from ECOSAT to PHREEQC is simple if one site is involved in the multinuclear surface complex, and the user simply has to add the logarithm of the denticity to the ECOSAT constant. In the respective examples in Figure 7 this simple modification exactly reproduces the ECOSAT calculations. The correction term amounts to 0.3 in $\log$ units and allows to reproduce the ECOSAT calculations in Figures 7 B, C, E and F. Note that the set-off in the calculations without correction is similar in all these cases. The situation is more complex if different sites participate in the multinuclear surface complex. In Figure $7 \mathrm{D}$ the set-off of the PHREEQC results compared to ECOSAT is much larger than in the previous cases. To reproduce the ECOSAT results for Figure 7 D, we recalculated the molar concentration scale constant using the ECOSAT inherent correction term and rescaled it to PHREEQC by the factor given in the PHREEQC manual. 


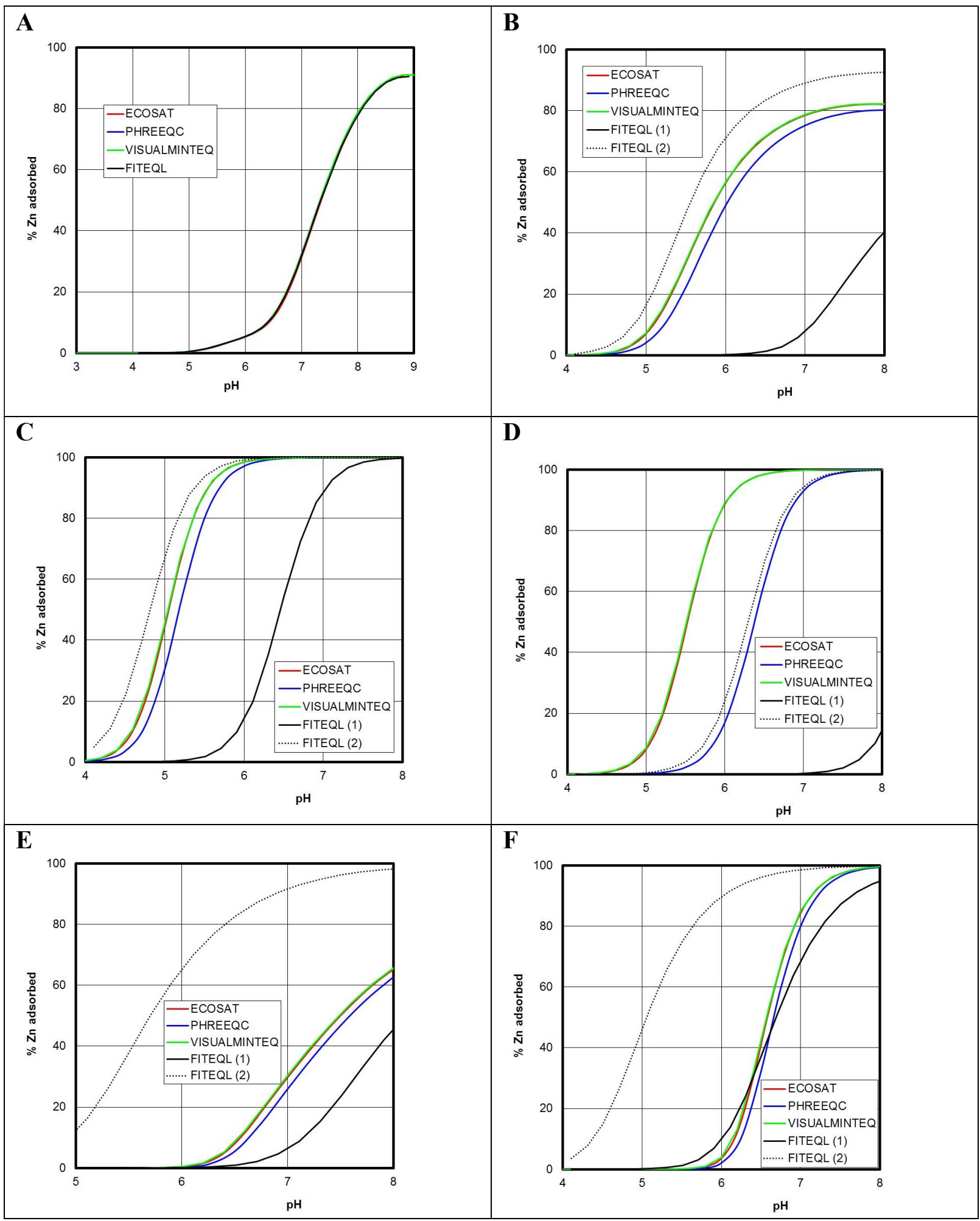

Figure 7. Zn adsorption edges on HFO (DLM in $100 \mathrm{mM}$ salt) (A) based on Dzombak and Morel (1990), (B) bidentate on the weak site, (C) bidentate on the weak site, with increase in solid concentration by a factor of 10, (D) bidentate involving both sites, (E) bidentate, binuclear on weak site, (F) bidentate, binuclear on weak site, with increase in solid concentration by a factor of 10 . All without conversions.

Conditions: A: 0.09 g/l HFO, $0.1 \mathrm{mM} \mathrm{Zn;} \mathrm{B:} 0.09$ g/1 HFO, $0.1 \mathrm{mM} \mathrm{Zn,} \mathrm{C:} 0.9$ g/l HFO, 0.1 mM Zn; D: 0.09 g/1 HFO, $0.1 \mu \mathrm{M}$ Zn, E: 0.09 g/l HFO, 0.1 mM Zn; F: 0.9 g/l HFO, 0.1 mM $\mathrm{Zn}$. 
For applications to reactive transport modelling, the user has to make sure whether codes use automated scaling procedures for multidentate surface complexes or not. This is particularly important, since the huge solid to liquid ratio that will be involved in reactive transport in porous media will require substantial corrections, if the intrinsic constants are implemented in the molar scale. As with PHREEQC, the outcome will depend on the code and model implementation.

\section{Diffuse double layer implementation}

The aim of the following modeling exercises was to illustrate what kind of diffuse double layer equation is implemented in the different codes. To this end, we did calculations within a surface complexation model framework that involves the diffuse layer part. We used a 1:1 electrolyte and a 2:1 electrolyte, as well as mixed electrolytes. From the output, we separated the calculated diffuse layer potential and the diffuse layer charge and the overall ionic strength. All the codes give these distinct values that have to satisfy the respective implemented equation (i.e. either (3) or (4)). The diffuse layer potential and the ionic strength were then inserted in equation 3 to yield the diffuse layer charge inherent to symmetrical electrolytes, and compared to the value obtained by the codes. If the results coincided for the 2:1 and mixed electrolytes, it was concluded that equation 3, and not the more general case, was used in a given code.

Table 1 summarizes the results.

Table 1: Types of equations implemented in four different popular speciation codes.

\begin{tabular}{|c|c|c|c|c|}
\hline Code & ECOSAT & PHREEQC & VISUALMINTEQ & FITEQL \\
\hline Equation & 4 & 4 & 3 & 3 \\
\hline
\end{tabular}


While for ECOSAT and FITEQL the expected results were obtained (here the documentation is clear), for PHREEQC and VISUALMINTEQ users can take advantage of the results of our calculations to choose the code that is appropriate for their respective applications.

\section{CONCLUSIONS}

The problem of conversions between various kinds of intrinsic adsorption constants has previously been little addressed because, for mono-dentate surface complexation, the values of $K_{M}^{\mathrm{int}, 1}$ expressed in any concentration scale are the same. For the same set of experimental data, the value of $K_{M}^{\mathrm{int}, 1}$ depends only on the chosen site density parameter $\Gamma_{S}$ or site capacity $q_{S}$, as already discussed in the literature (Lützenkirchen, 2002; Kulik, 2002, 2006, 2009; Sverjensky, 2003). But, although earlier studies have pointed to this issue (e.g. Venema et al., 1996), it has not yet been conclusively demonstrated how the large biases in $K^{\text {int }}$ values related to multiple denticity can be avoided by the appropriate scale conversions.

Modeling examples considered in this contribution demonstrate significant magnitudes of 'denticity effects', visible by code comparison and benchmarking. The effects arise from different implementations of the law of mass action and mass balance. Our results emphasize that the set of intrinsic equilibrium constants for the formation reactions of surface complexes must be consistent for all types of surface species, including multi-dentate complexes. It is imperative to document precisely the concentration scales and the assumptions on denticity to clarify the interpretation of experimental and modeling results. This is a prerequisite for future thermodynamic sorption databases, which also require a conventional agreement on standard- and reference states for the activities of surface complexes and surface sites, which is still to be reached (Kulik and Lutzenkirchen, 2011).

The present paper contributes to the resolution of two long-standing problems around surface complexation models. The first is associated with the proliferation of specific model 
setups in the literature, used to describe individual sorption data sets. While an adequate fit is invariably achieved in each specific case, the conversion of computed parameter values without the necessity of refitting experimental data sets is relevant. Ultimately internally consistent sets of intrinsic and standard-state constants for general surface complex stoichiometries are required and we will describe an approach towards this in detail elsewhere.

The second issue is how to apply adsorption equilibrium constants to 'real' systems with non-zero electrostatic potential and significant surface coverage, site saturation and competition effects involving multi-dentate $M$ surface species, possibly of different denticity, together with surface complexes of other ions. It is known that, at least for the electrolyte adsorption, fitted intrinsic adsorption constants depend on the choice of doubly layer model. To what extent in such cases a variation of the site density parameter and denticity may affect capacitance and $K^{\text {int }}$ values required to obtain a comparable fit to the experimental data (in particular, surface charge data), still remains to be studied. The available information for the constant capacitance model (Lützenkirchen, 1999) would suggest such interdependencies, largely neglected so far. In a thermodynamic sense, the introduction of concepts of chemical potential, activity and activity coefficients, and consideration of activity-composition relationships could account for non-ideality effects. While Coulombic terms (electrostatic activity coefficients) are generally accepted, non-electrostatic surface site saturation and competition effects, mostly related to various types of adsorption isotherms, still remain largely controversial.

Acknowledgments. The authors are grateful to the sponsors and participants in the Sorption Forum of the Nuclear Energy Agency, which has facilitated the open discussion of the issues raised in this paper. Many aspects considered in this paper were discussed at the Discussion Meeting "Surface Reactions and the Electrical Interfacial Layer: Experiments and Models - 
Towards a Common Basis", Opatija, Croatia, in October 2007. The authors acknowledge the reviews by two anonymous referees, which helped improve the manuscript.

\section{REFERENCES}

Benjamin, M.M., 2002. Modeling the mass-action expression for bidentate adsorption, Environ. Sci. Tech. 36, 307-313.

Bouby, M., Lützenkirchen, J., Dardenne, K., Preocanin, T., Denecke, M.A., Klenze, R., Geckeis, H., 2010. Sorption of Eu(III) onto titanium dioxide: Measurements and modeling. J. Colloid Interface Sci. $350,551-561$.

Davis, J. A. and Kent, D. B., 1990. Surface complexation modeling in aqueous geochemistry. In: Hochella, M. F. and White, A. F. (Eds.), Mineral-water interface chemistry. Reviews in Mineralogy 23, MSA, Washington, D.C.

Dent, A.J., Ramsay, J.D.F., Swanton, S.W., 1992. An EXAFS study of uranyl-ion in solution and sorbed onto silica and montmorillonite clay colloids. J. Colloid Interface Sci. 150, 45-60.

Dzombak, D. A. and Morel, F. M. M., 1990. Surface complexation modeling. Hydrous ferric oxide. Wiley Interscience, New York.

Greathouse, J. A., O’Brien, R. J., Bemis, G., Pabalan, R. T., 2002. Molecular dynamics study of aqueous uranyl interactions with quartz (010), J. Phys. Chem. B 106, 1646-1655

Guillamont, R., Fanghänel, Th., Fuger, J., Grenthe, I., Neck, V., Palmer, D.A., Rand, M.H., 2003.

Chemical Thermodynamics, Vol. 5. Update on the Chemical Thermodynamics of Uranium, Neptunium, Plutonium, Americium and Technetium (OECD Nuclear Energy Agency).

Gustafsson, J.P., and Lumsdon, D. G., 2014.Comment on "Citrate adsorption can decrease soluble phosphate concentration in soils: Results of theoretical modelling” by Marek Duputel, Nicolas Devau, Michel Brossard, Benoît Jaillard, Davey L. Jones, Philippe Hinsinger and Frédéric Gérard (2013), App. Geochem. 46, 85-89. 
Hiemstra, T., and van Riemsdijk, W.H., 2007. Adsorption and surface oxidation of Fe(II) on metal (hydr)oxides. Geochim. Cosmochim. Acta 71, 5913-5933.

Kallay, N., Preocanin, T., Kovacevic, D., Lützenkirchen, J., and Villalobos, M., 2011. Thermodynamics of the reactions at solid/liquid interfaces. Croatica Chemica Acta 84, 1-10.

Karamalidis, A.K., Dzombak, D.A., 2010. Surface complexation modeling: gibbsite. John Wiley \& Sons.

Kulik, D. A., 2002. Sorption modelling by Gibbs energy minimisation: Towards a uniform thermodynamic database for surface complexes of radionuclides. Radiochim. Acta 90, 815-832. Kulik, D. A., 2006a. Classic adsorption isotherms incorporated in modern surface complexation models: Implications for sorption of actinides. Radiochim. Acta 94, 765-778.

Kulik, D. A., 2006b. Standard molar Gibbs energies and activity coefficients of surface complexes (Thermodynamic insights). In: Lützenkirchen, J. (Ed.), Surface complexation modelling. Elsevier, Amsterdam.

Kulik, D. A., 2009. Thermodynamic concepts in modeling sorption at the mineral-water interface. In: Oelkers, E. H. and Schott, J. (Eds.), Thermodynamics and kinetics of water-rock interaction. Reviews in Mineralogy and Geochemistry 70, MSA\&GS, Washington, D.C.

Kulik, D.A., Lützenkirchen J., and Payne T.E., 2010. Consistent treatment of 'denticity' in surface complexation models. Abstract in: Goldschmidt'2010, Earth, Energy, and the Environment, Knoxville TN, USA,13-18 June 2010. Geochimica et Cosmochimica Acta 74,(12 Supplement 1), p.A544.

Kulik, D.A., and Lützenkirchen J., 2011. Consistent treatment of entropy, enthalpy and volume effects of multi-dentate adsorption reactions. Abstract in: Goldschmidt 2011: Earth, Life and Fire, Prague, Czech Republic, August 14-19, 2011. Mineralogical Magazine 75(3), p.1251.

Lützenkirchen, J., Behra, P., 1996. A new approach for modelling potential effects in cation adsorption onto binary (hydr)oxides, Journal of Contaminant Hydrology 26, 257-268.

Lützenkirchen, J., 2002. Surface complexation models of adsorption: a critical survey in the context of experimental data. Surfactant Science Series, 107, 631-710.

Lützenkirchen, J., 2004. Modelling uranyl adsorption to quartz - application of the CD-MUSIC concept, Geochim. Cosmochim. Acta 68, A502. 
Machesky, M. L., Wesolowski, D. J., Palmer, D. A., Ridley, M. K., Benezeth, P., Lvov, S. N., and Fedkin, M. V., 2006. Ion adsorption into the hydrothermal regime: experimental and modeling approaches. In: Lützenkirchen, J. (Ed.), Surface complexation modelling. Elsevier, Amsterdam. Mathur, S.S. and Dzombak, D.A., 2006. Surface complexation modeling. Goethite. In Surface complexation modelling (Ed. J. Lützenkirchen), Academic Press, London.

Peacock, C. L. and Sherman, D. M., 2004. Copper(II) sorption onto goethite, hematite and lepidocrocite: A surface complexation model based on ab initio molecular geometries and EXAFS spectroscopy. Geochim. Cosmochim. Acta 68, 2623-2637.

Ponthieu, M., Juillot, F., Hiemstra, T., van Riemsdijk, W. H., and Benedetti, M. F., 2006. Metal ion binding to iron oxides. Geochim. Cosmochim. Acta 70, 2679-2698.

Reich, T., Moll, H., Denecke, M.A., Geipel, G., Bernhard, G., Nitsche, H., 1996. Characterization of hydrous uranyl silicate by EXAFS. Radiochim. Acta 74, 219-223.

Reich, T., Moll, H., Arnold, T., Denecke, M.A., Hennig, C., Geipel, G., Bernhard, G., Nitsche, H., Allen, P.G., Bucher, J.J., Edelstein, N.M., Shuh, D.K., 1998. An EXAFS study of uranium(VI) sorption onto silica gel and ferrihydrite, J. Electron Spectr. Rel. Phen. 96, 237-243.

Sherman, D. M., 2009. Surface complexation modeling: Mineral fluid equilibra at the molecular scale In: Oelkers, E. and Schott, J. Eds.), Thermodynamic and kinetics of water-rock interaction. Reviews in Mineralogy and Geochemistry 70, MSA\&GS Washington, D.C.

Sherman, D. M., Peacock, C. L., and Hubbard, C. G., 2008. Surface complexation of U(VI) on goethite ( $\alpha-\mathrm{FeOOH})$. Geochim. Cosmochim. Acta 72 298-310.

Sigg, L., Stumm, W., 1996. Aquatische Chemie: eine Einführung in die Chemie wässriger Lösungen und natürlicher Gewässer", $4^{\text {th }}$ edition, Teubner, Stuttgart.

Sigg, L., Stumm, W., 1989. Aquatische Chemie: eine Einführung in die Chemie wässriger Lösungen und natürlicher Gewässer, Verlag der Fachvereine, Zürich.

Sigg, L., Stumm, W., Behra, P., 1992. Chimie des milieu aquatiques, Masson, Paris. p. 323

Stumm, W., 1992. Chemistry of the solid-water interface. Wiley-Interscience, New York.

Stumm, W., Morgan, J.J., 1996. Aquatic Chemistry: chemical equilibria and rates in natural waters, $3^{\text {rd }}$ edition, John Wiley \& Sons. 
Sverjensky, D. A., 2003. Standard states for the activities of mineral surface sites and species.

Geochim. Cosmochim. Acta 67, 17-28.

Sylwester, E. R., Hudson, E. A., and Allen, P. G., 2000. The structure of uranium(VI) sorption complexes on silica, alumina and montmorillonite. Geochim. Cosmochim. Acta 64, 2431-2438. Venema, P., Hiemstra, T., and van Riemsdijk, W.H. 1996. Multisite Adsorption of Cadmium on Goethite, J. Colloid Interf. Sci. 183, 515-527.

Wang, Z., and Giammar, D. E., (2013). Mass action expressions for bidentate adsorption in surface complexation modeling: Theory and practice. Environ. Sci.Tech., 47, 3982-3996.

Westall, J. C., Zachary, J. L., and Morel, F. M. M., 1986. MINEQL: A computer program for the calculation of the chemical equilibrium composition of aqueous systems. Department of Chemistry, Oregon State University, Corvallis, Oregon 97331.

Zhang, Z., Fenter, P., Cheng, L., Sturchio, N. C., Bedzyk, M. J., Predota, M., Bandura, A., Kubicki, J. D., Lvov, S. N., Cummings, P. T., Chialvo, A. A., Ridley, M. K., Benezeth, P., Anovitz, L., Palmer, D. A., Machesky, M. L., and Wesolowski, D. J., 2004. Ion adsorption at the rutile-water Interface: Linking molecular and macroscopic properties. Langmuir 20, 4954-4969.

Codes used

\section{ECOSAT:}

Keizer, M. G. and Van Riemsdijk, W. H., 1998. ECOSAT. Technical report. Department Soil Science and Plant Nutrition, Wageningen Agricultural University, Wageningen, The Netherlands.

Version 4.8

\section{FITEQL:}

Westall, J., 1982. FITEQL, A computer program for determination of equilibrium constants from experimental data, Version 2.0, Report 82-02, Department of Chemistry, Oregon State University, Corvallis, Oregon 97331. 
Herbelin, A. L. and Westall, J. C., 1996. FITEQL: A computer program for determination of chemical equilibrium constants from experimental data. Department of Chemistry, Oregon State University, Corvallis, Oregon 97331.

\section{PHREEQC:}

Parkhurst, D.L. and Appelo, C.A.J., 2004. PHREEQC: A computer program for speciation, batch reaction, one dimensional transport, and inverse geochemical calculation. User guide to PHREEQC. USGS Water-Resources Investigation Report 99-4259.

Version 2.18.00 was used.

\section{VISUALMINTEQ:}

http://www2.lwr.kth.se/English/Oursoftware/vminteq/

http://vminteq.lwr.kth.se/

Version 3.1 was used. 